\title{
Design and Simulation of Natural Gas Liquid Recovery Process from Rich Natural Gas
}

\author{
Hezekiah Braye Stephen \\ Department of Chemical/Petrochemical Engineering \\ Rivers State University, Nkpolu-Oroworukwo, Port Harcourt, Nigeria \\ Akpa Jackson Gonurubon \\ Department of Chemical/Petrochemical Engineering \\ Rivers State University, Nkpolu-Oroworukwo, Port Harcourt, Nigeria \\ Dagde Kekpugile Kenneth \\ Department of Chemical/Petrochemical Engineering \\ Rivers State University, Nkpolu-Oroworukwo, Port Harcourt, Nigeria \\ Adeloye Olalekan Michael* \\ Department of Chemical/Petrochemical Engineering \\ Rivers State University, Nkpolu-Oroworukwo, Port Harcourt, Nigeria
}

\begin{abstract}
Natural gas plays a growing role in the energy mix by displacing coal due to its relative economic and/or environmental advantages A process of natural gas liquid (NGL) recovery utilizing internally generated energy to achieve energy efficiency was designed. The process utilizes heat generated from the compressor end of the turboexpander to provide heat energy required to maintain the appropriate operating conditions at the intermediate and bottom sections of the demethanizer column, rather than utilizing dedicated steam generators that requires additional construction, installation, operations and maintenance cost. Simultaneously, the temperature of the hot residue gas is also dropped to the required range for export, rather than utilizing dedicated process gas coolers. The various unit operations such as heat exchangers, liquid separators, Joules Thompson Valve coefficient, demethanizer column, reflux condenser, and bottom reboiler were designed, and cost evaluation performed for each unit, while models were solved using MatLab software. The quality and composition of NGL and residue gas produced are consistent with industrial process plant data. In addition, condenser and reboiler showed that the heat removed from the condenser is $3.180 .5 \mathrm{~kW}$ and $1.65 \mathrm{~m}^{2}$ area was exchanged, while the heat for the reboiler is $474.5 \mathrm{~kW}$ at $47.25 \mathrm{~m}^{2}$ exchanged area. Also, the temperature profile of the demethanizer column is not uniform as lower temperature is required for the rectifying section (cryogenic absorption). Thus, temperature of $-90^{\circ} \mathrm{C}$ to $95^{\circ} \mathrm{C}$ favours the production of sales gas as the top product stream, while a temperature range of $30^{\circ} \mathrm{C}$ to $36^{\circ} \mathrm{C}$ at the bottom favours the recovery of NGL product as the bottom stream. The height and diameter of demethanizer column for distillation and absorption sections are $28 \mathrm{~m}$ and $1.55 \mathrm{~m}$ and $7.24 \mathrm{~m}$ and $3 \mathrm{~m}$ respectively.
\end{abstract}

Keywords: Natural Gas Liquid, Heat Exchanger, Separator, J-T Valve, Demethanizer Column,

DOI: $10.7176 / \mathrm{CPER} / 64-04$

Publication date: January $31^{\text {st }} 2022$

\section{Introduction}

The current renaissance in oil and natural gas production worldwide has provided economic benefits globally, through higher employment and lower energy prices(USEIA, 2018). The world's energy consumption trend is toward environmentally friendly fuels. Plentiful low-cost supplies and the expansion of liquefed natural gas (LNG) trade, in addition to the air quality policies, increase the share of natural gas (NG) in primary energy compared to the other fossil fuels(Sabbagh et al., 2020a). Natural gas plays a growing role in the energy mix by displacing coal due to its relative economic and/or environmental advantages in some markets. Today, its share in the energy mix is $23 \%$, compared to $21 \%$ in 2010 (Sabbagh et al., 2020b). There is massive oil and natural gas production growth, in that reserves that were termed unconventional or stranded have been tapped with economic gains. The application of horizontal drilling and hydraulic fracturing techniques in oil and gas production is among other technological factors that has revolutionized the energy system(USDE, 2018).Natural gas is a key component of global energy supply and the cleanest fossil fuel. It is the safest and most useful of all sources of energy(Kidnay et al, 2006). Raw natural gas production has increased since 2005 due to the increasing global demand for cleaner energy resources(Smith \& Doong, 2016, Pinto et al, 2016). Over, the years, the estimated volume of natural gas reserves globally has been on the rise. Increasing from an estimated value of 130.8trillion standard cubic meter (tscm) in 1998 to about $170.2 \mathrm{tscm}$ in $2008,196.1 \mathrm{tscm}$ in 2017 , and has further increased to about $196.9 \mathrm{tscm}$ in 2018(Statistical Review, 2019). 
Nigeria has the largest gas reserves in Africa and ninth in the world(Statistical Review, 2019), and the proven natural gas reserve presently is estimated to be about $5.7 \mathrm{tscm}$, while the unproven gas reserves is estimated to be about $17 \mathrm{tscm}$. However, only about $25 \%$ of these proven gas reserves are being produced or are under development currently. Nigeria's current gas production is about 241 million standard cubic meter per day (mmscm/d)(DPR, 2019). Furthermore, most of the associated gas produced are flared or re-injected into oil fields, due to the absence of commercial utilization of hydrocarbon gas. Associated gas wasted during flaring is estimated to cost Nigeria US \$2.5 billion on a yearly basis. So far, there have been no restrictions in Nigeria on the re-injection of any extra gas, but the rate of gas flared has significantly reduced in recent years. Nigeria's global ranking on gas flared has dropped from the 2 nd to the 5 th largest natural gas flaring country in the world according to Cedigaz and OPEC or 7th according to GGFR 2016(National Gas Policy, 2017). Many design options are available for improving the economics of natural gas processing and utilization in the gas industries. A viable option for natural gas monetization is the recovery of natural gas liquid (NGL), alongside conventional gas processing options such as natural gas liquefaction (LNG), gas to liquid (GTL), and gas to power (GTP)(Kofi, 2015). The volume of NGL available for extraction from natural gas depends on the amount of natural gas feed stock available to the processing plant and volume of NGL contained in the natural gas feed(Saeid et al., 2019). Also, the volume of NGL actually extracted during processing depends on process technology utilized for NGL recovery, NGL prices at the process plant, with respect to the market price considering the cost of transportation, economics of recovering ethane and processing contract terms (product specifications)(Towler \& Sinnott, 2013). The technologies for the recovery of NGL are not new, and a large number of different processes have been applied in the natural gas industry. One of the commonly applied NGL process uses a turbo-expander, due to its low energy demand and high product recovery(Pitman et al., 1998). Another option is the process that uses external refrigeration cycles. However this option can be cost-effective when the feed component ratio for $\mathrm{C}_{2}+$ is high(Jibril et al., 2005). More so, the Lean-oil absorption method of NGL production is less energy-efficient and much more complex than the turbo-expander method(Diaz et al., 1997). The price premium of NGL over natural gas was examined, thereby maximizing NGL production from an existing gas plant (Salam Gas Plant) by retrofitting the plant to include deethanizer and de-butanizer towers using HYSYS version 8.4. In order to meet the high demand of LPG in Egypt, 100 tons/day of LPG was targeted to be produced. However, the simulation process gave 88tons/day of LPG as against 56tons/day of LPG production that was obtainable before retrofitting. This modification has the advantage of producing liquefied petroleum gas (LPG) from the Natural gas liquid since the process of producing LPG from lighter hydrocarbon is far more expensive, and of no economic benefits. The study which was based on the economic analyzer of HYSIS showed that the two additional towers, associated equipment, and modification costs have high investment strength with a very short pay-back time(Bhran et al., 2016)

Besides, NGL recovery has become increasingly economically attractive since some of its components $\left(\mathrm{C}_{2}\right.$, $\mathrm{C}_{3}, \mathrm{C}_{4}$ ) are often isolated by fractionation or distillation processes and sold separately. There are numerous methods used to increase NGL recovery from a feed gas, with potential enhancements involving integrated processes(Elliot et al., 2005). In a typical NGL plant, various components of NGLs are separated one by one from the natural gas stream applying different types of fractionation columns (demethanizer, deethanizer, depropanizer and debutanizer) in series(Ali et al., 2015). Rezakazemi et al., (2017) worked to investigate the production of LPG by fractionation process of different NGL's. The simulation of the distillation columns was done using Aspen HYSYS. From the results, it was highlighted that using a debutanizer column before a depropanizer is a better option for the process, in terms of ease of stage separation and economics. Tomlinson et al., (1990) studied the recovery of NGL from hydrocarbon gas feed stock by partial condensation of the feed in a heat exchanger at super atmospheric pressure. Heat exchange between streams can be properly managed by the heat integration method(Klemes et al., 2010). If operating conditions are altered, the potential for energy recovery within the process also changes accordingly. So it is very important to note that improving the heat recovery in an NGL process should be considered together with determining the design and operating conditions of the entire process(Ghorbani et al., 2012). The design of NGL processes requires the simultaneous consideration of column design, heat recovery, and power recovery. The modeling and simulation of NGL processes gives engineers more understanding of these interactions, thereby allowing for improved solutions with better recovery and economics(Jibril et al., 2005). Modern floating and onland natural gas liquefaction (NGL) plants employ direct sequences of three or more distillation columns to recover $\mathrm{C} 1$ to $\mathrm{C} 5+$ hydrocarbons according to specific site requirements(Halvorsen et al., 2018). The current global population growth and high demand for NGL in the energy and petrochemical markets, it becomes necessary to look at methods of optimizing NGL production utilizing energy efficiency options to make the different grades of stranded gas reserves (lean or rich gas) economical. The demethanizer column of conventional NGL production plants utilises a bottom reboiler and other associated heat exchangers that uses steam as the source of hot fluid to achieved the desired bottom temperature of the NGL product, and also maintain required temperature distribution at the lower section of the column, while the lean sales gas (methane) that exits the column at sub-zero temperature is preheated and compressed at the compressor end of the turbo-expander. This study focuses on utilizing heat energy generated from hot process gas in the NGL recovery process, to serve as hot fluid for the reboilers and heat 
exchangers of the Demethanizer Column, thereby eliminating additional cost of installing and maintaining steam generators, and process fan coolers. Therefore, this study is aimed at designing and simulating the processes of natural gas liquid (NGL) production from rich natural gas by utilizing internally generated energy, and this will be achieved by designing NGL recovery process, its process simulation and economics analysis.

\section{Process Description}

Rich natural gas after dehydration and sweetening treatments is the feed gas that enters the tube end of the $1^{\text {st }}$ heat exchanger at $80 \mathrm{bar}$ and $25^{\circ} \mathrm{C}$, precooled (stream 1) to $-23^{\circ} \mathrm{C}$ before entering the two phase separator at 79 bar. While the lean sales gas gains heat from the shell side of same heat exchanger (from -34 to $10^{\circ} \mathrm{C}$ ) and feeds the compressor end of the turbo-expander. At the two phase separator, the feed gas (stream 1) is flashed, thus separating some heavy ends as bottom product (stream 2) and goes into the demethanizer column, while the top product is split into two streams; one stream (stream 3) goes into the expander end of the turbo-expander unit for expansion, while the other top stream from the separator (stream 7) flow through the reflux condenser into the absorber section of the demethanizer column alongside the reflux stream (stream 8). The turbo-expander plant recovers liquid hydrocarbons from the natural gas inlet stream by changing the condition of the gas, so that the equilibrium between the various components is upset, causing some components to condense and others to vaporize in an attempt to reach a new equilibrium. The inlet gas temperature of the expander is decreased from $-23^{\circ} \mathrm{C}$ to $-78^{\circ} \mathrm{C}$ during the expansion process, and then fed into the demethanizer column above the top tray. Refrigeration produced by the expander is due to decrease in enthalpy of the gas stream. An expander by-pass valve (generally referred to as the JT Valve) is provided, which is normally closed during operation and used during plant start-up or when gas volume in excess of the expander design is being processed. Other associated units with the demethanizer column include reboiler, condenser and heat exchangers for effective process recovery and energy efficiency. The operating pressure of the demethanizer column is $24 \mathrm{bar}$, while the temperature profile varies from top to bottom. The temperature of the lean residue gas (sales gas) from the top of the column is $-95^{\circ} \mathrm{C}$, while the temperature of NGL produced at the bottom of the column is about $34{ }^{\circ} \mathrm{C}$. The process streams of the different stage of NGL recovery in Figure 1 are defined thus.

1. Precooled Feed Gas from the outlet of the $1^{\text {st }}$ Heat Exchanger into the Liquid Separator.

2. Bottom Product of the Liquid Separator into the Demethanizer Column.

3. Top Product of Liquid Separator into the inlet of the Expander section of the Turbo-Expander Unit.

4. Feed gas that has undergone isentropic expansion across the Expander Unit into the Demethanizer Column.

5. 5. Feed gas that has undergone isenthalpic expansion across the JT Valve into the Demethanizer Column.

6. Commingled Hydrocarbon feed from the Expander and the JT Valve into the Demethanizer.

7. Top Product of the Liquid Separator into the inlet of the Reflux Condenser Unit.

8. Reflux stream into the absorber section of the Demethanizer Column.

9. Lean Sales Gas from the top of the Demethanizer Column into the Reflux Condenser.

10. Lean Sales Gas on the outlet of the Reflux Condenser into the inlet of the shell side of the $1^{\text {st }}$ Heat Exchanger to gain more heat.

11. Lean Sales Gas from the outlet of the shell side of the $1^{\text {st }}$ Heat Exchanger into the suction end of the Compressor Unit of the Turbo-Expander.

12. Lean Gas from the discharge end of the Compressor Unit into the Bottom Reboiler, $2^{\text {nd }}$ and $3^{\text {rd }}$ Heat Exchangers to undergo heat loss before shipment.

13. Lean Sales Gas for shipment to LNG Plant.

14. NGL produced from the bottom of the Demethanizer Column.

15. Cold fluid from Demethanizer into the shell side of the $2^{\text {nd }}$ Heat Exchanger to gain heat.

16. Hot fluid from the shell side of the $2^{\text {nd }}$ Heat Exchanger to the Demethanizer for heat loss.

17. Cold fluid from the Demethanizer to the shell side of the $3^{\text {rd }}$ Heat Exchanger to gain heat.

18. Hot fluid from the shell side of the $3^{\text {rd }}$ Heat Exchanger to the Demethanizer for heat loss.

19. Cold fluid from the Demethanizer into the shell side of the Bottom Reboiler to gain heat.

20. Hot fluid from the shell side of the Bottom Reboiler into the Demethanizer for heat loss. 


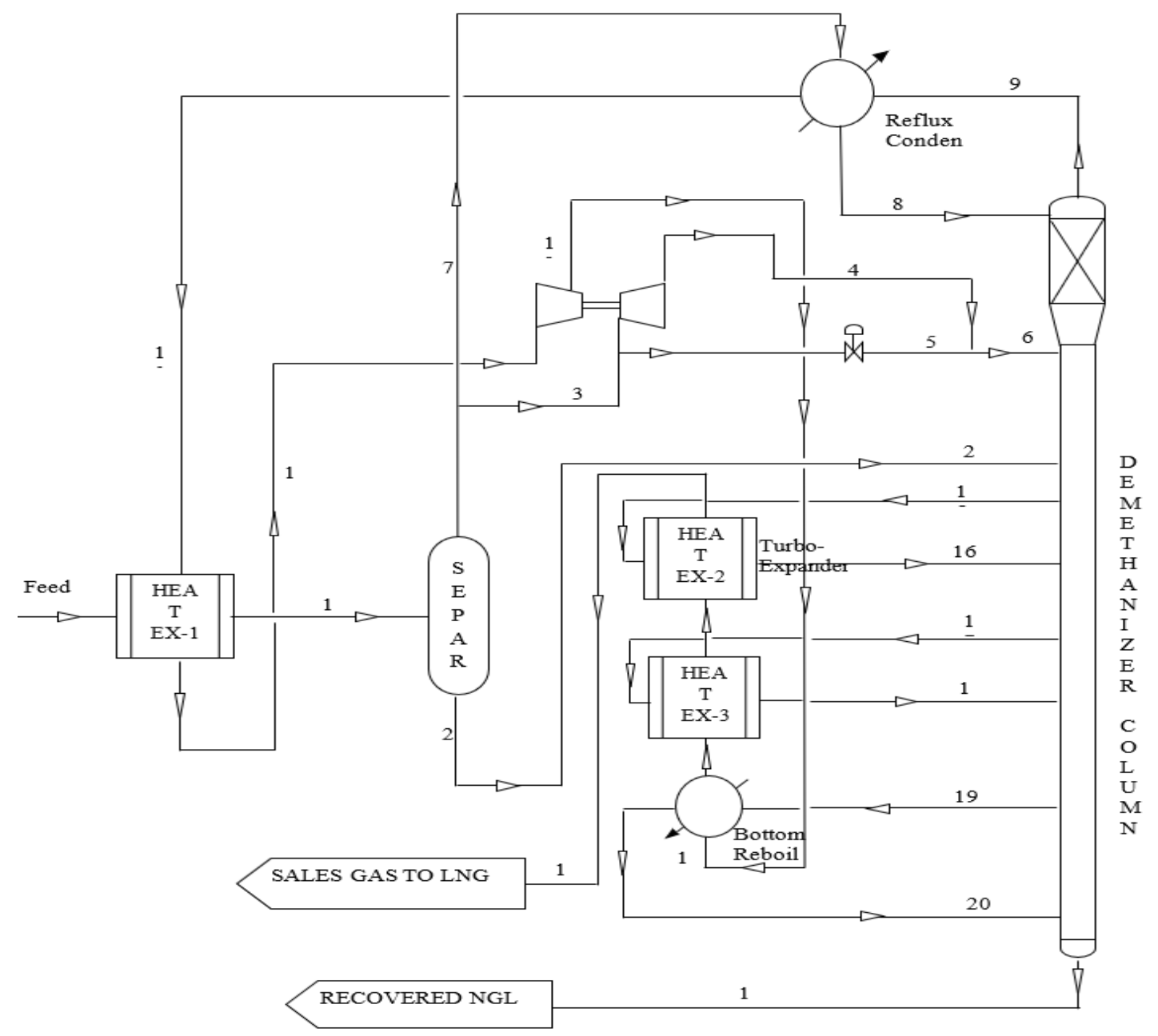

Figure 1: Process Flow Diagram of NGL Recovery Process

\section{MATERIAL AND METHODS}

The study utilized rich natural gas as feedstock with process units such as heat exchangers, separator, turboexpander, Joule Thompson valve, condenser, reboilers and de-methanizer column.

\subsection{Feed Characterization}

The feed gas is treated rich natural gas (dehydrated and sweetened) with molecular weight of $19.97 \mathrm{Kg} / \mathrm{Kmol}$, flow rate of $79.3 \mathrm{Kg} / \mathrm{s}$ and operating condition of $80 \mathrm{bar}$ and $25^{\circ} \mathrm{C}$ respectively.

Table 1: Composition of Treated Rich Natural Gas for NGL Recovery(ENI Spa, 2010)

\begin{tabular}{ll}
\hline COMPOSITION & MOL \% \\
\hline $\mathrm{H}_{2} \mathrm{O}$ & 0 \\
$\mathrm{~N}_{2}$ & 0.07 \\
$\mathrm{CO}_{2}$ & 0 \\
$\mathrm{C}_{1}$ & 84.55 \\
$\mathrm{C}_{2}$ & 7.55 \\
$\mathrm{C}_{3}$ & 4.83 \\
$\mathrm{iC}_{4}$ & 0.85 \\
$\mathrm{NC}_{4}$ & 1.13 \\
$\mathrm{iC}_{5}$ & 0.32 \\
$\mathrm{NC}_{5}$ & 0.22 \\
$\mathrm{NC}_{6}$ & 0.29 \\
$\mathrm{NC}_{7}$ & 0.13 \\
$\mathrm{NC}_{8}$ & 0.05 \\
$\mathrm{NC}_{9}$ & 0.01 \\
Total & $\mathbf{1 0 0}$
\end{tabular}




\subsection{NGL Process Recovery Units}

The unit operation equipments applied in this study are discussed thus.

\subsubsection{Heat Exchangers}

Three heat exchangers are involved in this study. The first exchanger primary function is to precool the feed gas before being flashed at the two phase separator, and simultaneous heat up the residue gas from the reflux condenser to the required temperature for compression at the compressor end of the turbo-expander. The feed gas flow at an inlet temperature of $T_{1}=298 \mathrm{~K}$ and outlet temperature of $T_{2}=250 \mathrm{~K}$ at mass flow rate of $79.3 \mathrm{Kg} / \mathrm{s}$, while the second and third exchangers utilizees internally generated heats to ensure proper temperature distribution at the intermediate and bottom sections of the column, thereby enhancing effective recovery process of the desired product and product stability. Therefore, the following assumptions are taken in designing the exchanging unit: pressure drop is directly proportional to fluid velocity, tube side fluid velocity is higher than the shell side fluid velocity and steady state operational process. The differential energy balance equation for shell and tube heat exchanger yielded

Tube side

$\frac{d T}{d x}=-\frac{2 U \pi\left(\mathrm{T}_{\text {in }}-\mathrm{T}_{\text {out }}\right)}{v \rho C_{P} r}$

The heat transfer coefficient, $h_{i} * \frac{D}{k}=1.86 *\left(\frac{D}{L} * R_{e} * P_{r}\right)^{0.33}\left(\frac{\mu}{\mu_{w}}\right)^{0.14}$

Pressure drop $\Delta P_{t}=N_{p}\left[8 j_{f}\left(\frac{L}{d_{i}}\right)+2.5\right] \frac{\rho u_{t}^{2}}{2}$

Shell side

$\frac{d T}{d x}=-\frac{2 U \pi r t u b e\left(\mathrm{~T}_{\text {in }}-\mathrm{T}_{\text {out }}\right)}{v \rho C_{P}\left(r^{2} \text { shell }-r^{2} \text { tube }\right)}$

The heat transfer coefficient, $\mathrm{h}_{\mathrm{o}}=\left(\mathrm{J}_{\mathrm{n}}\right)\left(\frac{\mathrm{k}}{\mathrm{d}_{e}}\right)\left(\mathrm{R}_{\mathrm{e}}\right)\left(\mathrm{P}_{\mathrm{r}}\right)^{0.33}\left(\frac{\mu}{\mu_{w}}\right)^{0.14}$

Pressure drop, $\Delta P=\frac{f G_{S}^{2} \mathrm{D}_{S}(N+1)}{\text { number of shell passes } * 5.22 * 10^{10} * \mathrm{D}_{e^{* \mathrm{~s}}}}$

The overall heat transfer coefficient, $\frac{1}{\mathrm{U}_{o}}=\frac{1}{\mathrm{~h}_{o}}+\frac{1}{\mathrm{~h}_{o d}}+\frac{d_{o} \times \operatorname{In} \frac{d_{o}}{d_{1}}}{2 k}+\frac{d_{o}}{d_{1}} \times \frac{1}{\mathrm{~h}_{i d}}+\frac{1}{\mathrm{~h}_{i}}$

Number of baffles $+1=\frac{L}{\mathrm{l}_{O}}$

Reynold's number, $\mathrm{R}_{\mathrm{e}}=\frac{\mathrm{pd}_{1} \mathrm{v}}{\mu}$

Prandlt number $\mathrm{P}_{\mathrm{r}}=\frac{\mathrm{C}_{p} \times \mu}{\mathrm{k}}$

3.2.2 Two Phase Separator

The volumetric flow rate of fluid entering the separator, its diameter and length are expressed thus.

$Q_{o} t=\frac{\pi(1.5 D) D^{2}}{4}$

$D s=\left(\frac{4 Q_{o} t}{1.5 \pi}\right)^{1 / 3}$

$L s=1.5\left(\frac{4 Q_{o} t}{1.5 \pi}\right)^{1 / 3}$

\subsubsection{Turbo-Expander}

Turbo-Expanders are centrifugal or axial-flow turbines, across which a high-pressure gas is expanded to produce work, which is often used to drive a compressor or generator. Since work is extracted from the expanding highpressure gas, the expansion process is considered an isentropic process. Turbo-Expander modeling yielded overall mass and energy balance of both the compressor and expander ends at steady state.

\section{Compressor End}

$\dot{W}_{c o}=\dot{m}\left(h_{2}-h_{1}\right)$

Expander End

$\dot{W}_{\text {ex }}=$ ḿ $\left(h_{4}-h_{3}\right)$

Since the work produced by the Expander is used to drive the Gas Compressor, then;

$\dot{W}_{\text {ex }}=\dot{W}_{c o}$

$\frac{\dot{m}}{\dot{m}}=M=\frac{\left(h_{2}-h_{1}\right)}{\left(h_{4}-h_{3}\right)}$

\subsubsection{Joule Thompson (J-T) Valve}

Joule-Thompson valve works by expanding the working fluid such as natural gas. Thus, the initial pressure upstream of the J-T Valve is higher than the final pressure downstream, leading to no change in kinetic energy for the Joule-Thompson expansion effect. The rate of work done by J-T valve is estimated as 


$$
\dot{\mathrm{W}}_{\mathrm{JT}}=\left(\frac{\mathrm{\eta}_{\mathrm{TT}} \mathrm{RT}_{1}}{\zeta-1}\right)\left[\left(\frac{\mathrm{P}_{2}}{\mathrm{P}_{1}}\right)^{\left(\frac{\zeta-1}{\zeta}\right)}-1\right]
$$

\subsubsection{Reflux Condenser}

The design of direct contact condenser is carried out, which is similar to the shell and tube exchanger design but wider baffle spacing are typically considered. Assuming the condensate flow smoothly from row to row under laminar flow regime, the Nusselt model is expressed as:

$\left(h_{c}\right)_{N_{r}}=\left(h_{c}\right)_{1} N_{r}^{-\frac{1}{4}}$

By Kern's method, mean condensation film coefficient for the tube bundle,

$$
\left(h_{c}\right)_{b}=0.95 K_{L}\left[\frac{\rho_{L}\left(\rho_{L}-\rho_{v}\right) g}{\mu_{L} \Gamma_{h}}\right]^{1 / 3} N_{r}{ }^{-\frac{1}{6}} \quad \text { and } \Gamma_{h}=\frac{W_{c}}{L N_{t}}
$$

The overall transfer coefficient of the condenser $\frac{1}{U}=\frac{1}{h_{o}}+\frac{1}{h_{o d}}+d_{o} \frac{n^{d_{o}} / d_{i}}{2 K_{W}}$

\subsubsection{Reboiler}

The modified Zuber equation for the heat flux of the reboiler is expressed as:

$q_{c b}=K_{b}\left(\frac{P_{t}}{d_{o}}\right)\left(\frac{\lambda}{\sqrt{N_{t}}}\right)\left[\sigma_{g}\left(\rho_{L}-\rho_{v}\right) \rho_{v}^{2}\right]^{0.25}$

The liquid level and shell should at least be $0.25 \mathrm{~m}$ and to avoid excessive entrainment, the maximum vapour velocity, $\mu_{v}(\mathrm{~m} / \mathrm{s})$ at the liquid surface is given as $\grave{\mu_{v}}<0.2\left[\frac{\rho_{L}-\rho_{v}}{\rho_{v}}\right]^{0.5}$

The overall heat transfer coefficient, $\frac{1}{U_{o}}=\frac{1}{h_{o}}+\frac{1}{h_{o d}}+d_{o} \frac{h^{d_{o}} / d_{i}}{2 K_{w}}+\frac{d_{o}}{d_{i}}\left(\frac{1}{h_{i}}+\frac{1}{h_{i d}}\right)$

The mean temperature difference, $\Delta \mathrm{T}_{m}=T_{s}-T_{f}$

\subsubsection{Demethanizer Column}

The Demethanizer Column is made up of the upper and lower sections. The upper section operates as an absorber column, while the lower section operates as a distillation column.

\subsubsection{Lower Demethanizer Column}

The lower demethanizer column is considered as a distillation column for the separation of methane and NGL from rich natural gas feed. The operating line equations for rectifying and stripping section of the column are $y_{n}=$ $\frac{L_{n}}{V_{n}} x_{n}+\frac{D}{V_{n}} x_{D}$ and $y_{m}=\frac{L_{m}}{V_{m}} x_{m}-\frac{B}{V_{m}} x_{f}^{\prime} \quad$ respectively.

The actual number of plates in the column is deduced by applying McCabe Thiele approach. Hence, the equilibrium data is plotted with the two operating line equations to get the McCabe Thiele diagram which gave the theoretical number of plates, and with column efficiency of $60 \%$, the actual number of plates is estimated

No of actual plates $=\frac{\text { No.of Theoritical plates }}{E_{0}(60 \%)}$

Also, the column diameter and height at $20 \%$ allowance is deduced as $D_{c}=\left(\frac{4 A_{c}}{\pi}\right)^{1 / 2}$ and

$\mathrm{Hc}=($ No of trays/ plates $) * t_{t}$ respectively.

The energy balance equation at steady state on the lower demethanizer column yielded

$\mathrm{Q}_{\mathrm{F}}+\mathrm{Q}_{\mathrm{R}}-\left(\mathrm{Q}_{\mathrm{B}}+\mathrm{Q}_{\mathrm{V}}\right)=0$

$\mathrm{Q}_{\mathrm{V}}=\mathrm{V}_{\mathrm{n}} \lambda_{\mathrm{m}}, \mathrm{Q}_{\mathrm{F}}=\mathrm{FCp}_{\mathrm{av}}\left(\mathrm{T}_{\mathrm{fs}}-\mathrm{T}_{\mathrm{f}}\right), \mathrm{Cp}_{\mathrm{av}}=\left(\mathrm{x}_{\mathrm{f}} \mathrm{Cp}_{\mathrm{m}}+\mathrm{x}_{\mathrm{w}} \mathrm{Cp}_{\mathrm{w}}\right), \mathrm{Q}_{\mathrm{B}}=\mathrm{BC}_{\mathrm{p}_{\mathrm{B}}}\left(\mathrm{T}_{\mathrm{B}}-\mathrm{T}_{\mathrm{f}}\right)$, and

$\mathrm{Q}_{\mathrm{R}}=\dot{m}_{h} h_{s}=B \lambda_{s}$

\subsubsection{Upper Demethanizer Column}

The methane-NGL mixture enters this column, where NGL is absorbed, recovered and flow downward into the distillation Section and pure methane is recovered at the top as sales gas. The mass transfer coefficients for both liquid and gas are

$$
\begin{aligned}
& K_{L}\left(\frac{\rho_{C}}{\mu_{g}}\right)^{1 / 3}=0.0051\left(\frac{L_{i}^{*}}{a_{w} u_{L}}\right)^{2 / 3}\left(\frac{\mu_{L}}{\rho_{C} D_{C}}\right)^{1 / 2}(a d p)^{0.4} \\
& K_{G}\left(\frac{R T}{a D_{v}}\right)=K_{5}\left(\frac{G_{i}^{*}}{a D_{v}}\right)^{0.7}\left(\frac{\mu_{v}}{\rho_{g D_{v}}}\right)^{1 / 3}\left(a d_{p}\right)^{-2.0}
\end{aligned}
$$

Hence, the liquid and gas height of transfer unit are $H_{L}=\frac{L_{m}}{K_{L} a_{w} C_{t}}$, $\mathrm{m}$ and $\mathrm{H}_{\mathrm{G}}=\frac{G_{m}}{K_{G} a_{w} P}$ respectively.

Also, $\mathrm{H}_{\mathrm{OG}}=\mathrm{H}_{\mathrm{G}}+\frac{m G_{m}}{L_{m}} \mathrm{H}_{\mathrm{L}}$ and $\mathrm{Z}=\mathrm{N}_{\mathrm{OG}} \mathrm{H}_{\mathrm{OG}}$

For allowance, the overall height of the Absorber Column is $Z_{T}=(1.30) Z$ and $C_{t}=\frac{\rho_{L}}{M_{S}}$

\subsubsection{Equipment Cost}

The model for the cost of equipments such as heat exchanger, distillation column, reflux reboiler and condenser is stated(Sinnoth \& Towler, 2009) as 
Total cost $=\mathrm{BVC}+$ Cost of Plates

For separator vessel is expressed as $C_{e}=C S^{n}$

\subsection{Process Operating Parameters}

The operating parameters (input data) for the simulation of heat exchangers, J-T Valve, Turbo-Expander and Demethanizer are highlighted.

Table 2: Data for Heat Exchanger Design

\begin{tabular}{|c|c|c|c|}
\hline Variables & $1^{\text {st }}$ Heat Exchanger & $\begin{array}{c}\text { Values } \\
2^{\text {nd }} \text { Heat } \\
\text { Exchanger } \\
\end{array}$ & $3^{\text {rd }}$ Heat Exchanger \\
\hline \multicolumn{4}{|c|}{ Hot Fluid } \\
\hline Inlet Temperature $\left(T_{1}\right)$ & $298 \mathrm{~K}$ & $311 \mathrm{~K}$ & $343 \mathrm{~K}$ \\
\hline Outlet Temperature $\left(\mathrm{T}_{2}\right)$ & $250 \mathrm{~K}$ & $293 \mathrm{~K}$ & $313 \mathrm{~K}$ \\
\hline Mass Flow Rate (m) & $79.31 \mathrm{Kg} / \mathrm{s}$ & $57.28 \mathrm{Kg} / \mathrm{s}$ & $57.28 \mathrm{Kg} / \mathrm{s}$ \\
\hline \multicolumn{4}{|c|}{ Cold Fluid } \\
\hline Inlet Temperature $\left(T_{1}\right)$ & $218 \mathrm{~K}$ & $241 \mathrm{~K}$ & $249 \mathrm{~K}$ \\
\hline Outlet Temperature $\left(\mathrm{T}_{2}\right)$ & $283 \mathrm{~K}$ & $281 \mathrm{~K}$ & $305 \mathrm{~K}$ \\
\hline Mass Flow Rate (m) & $57.28 \mathrm{Kg} / \mathrm{s}$ & $27 \mathrm{Kg} / \mathrm{s}$ & $27 \mathrm{Kg} / \mathrm{s}$ \\
\hline
\end{tabular}

Table 3: Data for Heat Exchanger, J-T Valve, Turbo-Expander and Demethanizer

\begin{tabular}{|c|c|c|c|c|}
\hline $\mathbf{S} / \mathbf{N}$ & & Parameters & Value/unit & \\
\hline & \multirow[t]{4}{*}{1.} & Natural gas & & \\
\hline & & Pressure, Pi & 80bars & \\
\hline & & Temperature, $\mathrm{T}$ & $50^{\circ} \mathrm{C}$ & \\
\hline & & Volumetric flow Rate, Q & $320 \mathrm{~m}^{3} / \mathrm{hr}$ & \\
\hline & \multirow[t]{4}{*}{2.} & Heat Exchanger (Sub-Cooled System) & & \\
\hline & & & Initial & Final \\
\hline & & Temperature & $50^{\circ} \mathrm{C}$ & $-25^{0} \mathrm{C}$ \\
\hline & & Pressure & $80 \mathrm{bar}$ & $79 \mathrm{bar}$ \\
\hline & \multirow[t]{3}{*}{3.} & Joule-Thomson Value & & \\
\hline & & III. Pressure & $75 \mathrm{bar}$ & 24bar \\
\hline & & II. Temperature & $-25^{0} \mathrm{C}$ & $-80^{\circ} \mathrm{C}$ \\
\hline & \multirow[t]{3}{*}{4.} & Turbo-Expander & & \\
\hline & & Pressure & $75 \mathrm{bar}$ & $24 \mathrm{bar}$ \\
\hline & & Temperature & $-25^{\circ} \mathrm{C}$ & $-80^{\circ} \mathrm{C}$ \\
\hline & \multirow[t]{3}{*}{5.} & Demethanizer Column & & \\
\hline & & i. $\quad$ Pressure & $24 \mathrm{bar}$ & $24 \mathrm{bar}$ \\
\hline & & Temperature & $-80^{\circ} \mathrm{C}$ & $-95^{0} \mathrm{C}$ \\
\hline & \multirow[t]{2}{*}{6.} & Heat capacity ratio & & \\
\hline & & $\zeta=C_{p} /$ & 1.32 & \\
\hline & 7. & $\begin{array}{l}\text { Cubic coefficient of } \\
\text { thermal expansion, } \alpha \text {. }\end{array}$ & $340 \times 10^{-6} \mathrm{~K}^{-1}$ & \\
\hline & \multirow[t]{3}{*}{8.} & Critical values (c) & & \\
\hline & & Pressure, $\mathrm{Pc}$ & 46bar & \\
\hline & & Temperature, Tc & $190.55 \mathrm{~K}$ & \\
\hline & \multirow[t]{3}{*}{9.} & Specific heat at & & \\
\hline & & Constant pressure & $\mathrm{C}_{\mathrm{p}}=35.8 \mathrm{~J} / \mathrm{molK}$ & \\
\hline & & ii. Constant volume & $\mathrm{C}_{\mathrm{v}}=27.4 \mathrm{~J} / \mathrm{mol} . \mathrm{K}$ & \\
\hline
\end{tabular}




\section{RESULTS AND DISCUSSION}

The results of the NGL recovery process units using MatLab software are discussed thus.

\subsection{Sales Gas and NGL Produced}

The produced residue gas (sales gas) is mainly methane gas with a molecular weight of $16.16 \mathrm{Kg} / \mathrm{kmol}$, flow rate of $57.28 \mathrm{Kg} / \mathrm{s}$, temperature of $-90^{\circ} \mathrm{C}$, pressure of $24 \mathrm{bar}$ and compositions of $\mathrm{C}_{1}(99.17 \%)$ and nitrogen gas $(0.08 \%)$, while the NGL produced from the bottom of the demethanizer column has specific gravity of 0.470 , flow rate of $27 \mathrm{Kg} / \mathrm{s}$, temperature of $28^{\circ} \mathrm{C}$, pressure of $24 \mathrm{bar}$ and compositions are $\mathrm{C}_{1}(0.45 \%), \mathrm{C}_{2}(31.94 \%), \mathrm{C}_{3}(31.66 \%), \mathrm{iC}_{4}$ $(8.9 \%), \mathrm{nC}_{4}(11.57 \%), \mathrm{iC}_{5}(4.39 \%), \mathrm{nC}_{5}(3.42 \%), \mathrm{C}_{6}(3.06 \%)$ and $\mathrm{C}_{7+}(4.61 \%)$.

\subsection{Heat Exchanger Analysis}

The simulated results of the heat exchanger depicted that the variation of temperature with length decreases exponentially in the tube-side (hot fluid) and increases in the shell side (cold fluid) and steadily tend towards linearity along the exchanger length with time due to heat lost and gain concurrently by the flow of fluids in the tube and shell sides of the Heat Exchanger as shown $n$ Figure 2

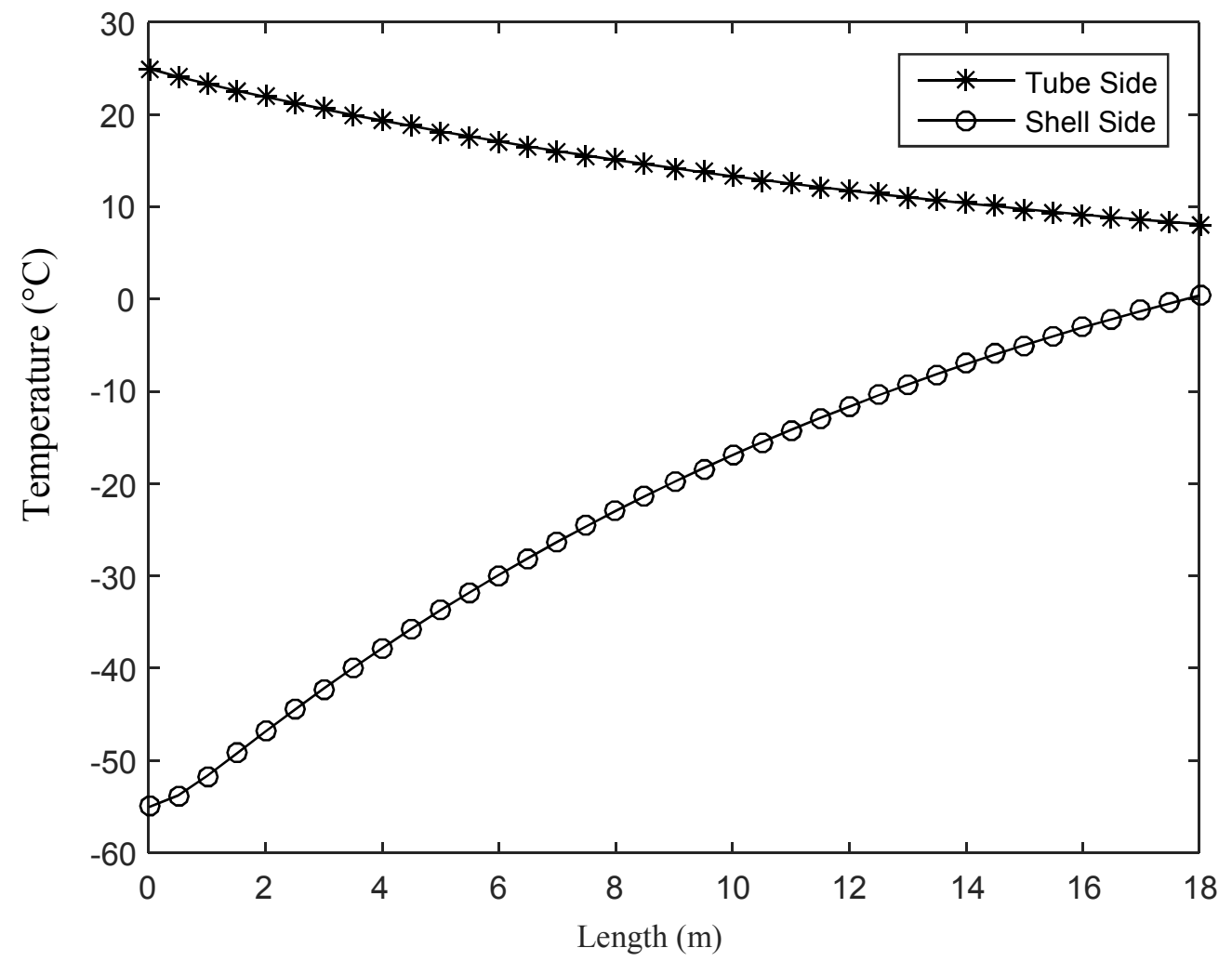

Figure 2: Temperature Profile Showing Heat Lost and Gain in the First Heat Exchanger

\subsection{Separator}

The size of the separator depends on residence time, flow rate and operating pressure, thus, the more the volume of the product for separation, the larger the size of the separator required. The design was done to make the separator fit for purpose, such that it can handle the desired pressure and volumetric flow rate of the feed, at optimal cost and energy consumption.

Table 4: Specification of Separator

\begin{tabular}{cccc}
\hline S/N & Parameter & Value & Unit \\
\hline 1 & Qo (volumetric flow rate) & 7.33 & $\mathrm{~m}^{3} / \mathrm{s}$ \\
2 & Residence Time, $\mathrm{t}$ & 10 & $\mathrm{Sec}$. \\
3 & Volume, $\mathrm{V}_{\mathrm{S}}$ & 73.3 & $\mathrm{~m}^{3}$ \\
4 & ${\text { Diameter, } \mathrm{D}_{\mathrm{S}}}_{5}$ & 2.65 & $\mathrm{M}$ \\
5 & Length, $\mathrm{L}_{\mathrm{S}}$ & 13.26 & $\mathrm{M}$ \\
\hline
\end{tabular}

\subsection{J-T Valve Coefficient}

Joule-Thompson coefficient is vital in the design because of its application in NGL production, especially during start-up of the process and low energy consumption. As shown in Figure 3, the energy needed for J-T valve 
operation is actually very small, and measured in absolute values. At absolute values range of $175 \mathrm{~K}$ to $300 \mathrm{~K}$, the $\mathrm{J}-\mathrm{T}$ Valve coefficient ranged from $0.05 \mathrm{~K} / \mathrm{J}$ to $0.13 \mathrm{~K} / \mathrm{J}$, which is very small and good for start-up of the process. The J-T Valve also serve as backup if on demand, the desired production rate exceeds the capacity of the TurboExpander.

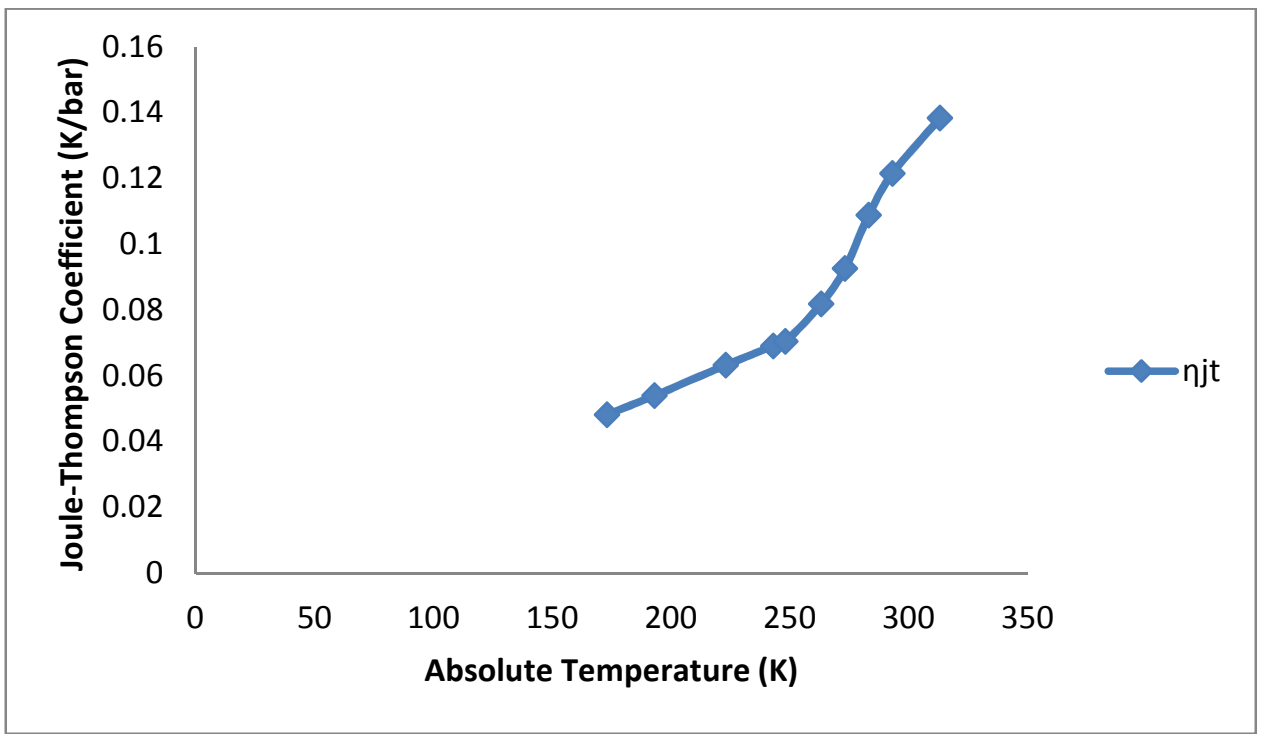

Figure 3: Variation of Joule-Thompson Coefficient versus Absolute Temperature

Furthermore, the J-T work depends on the absolute temperature values that ranges from $155 \mathrm{~K}$ to $200 \mathrm{~K}$, for $5 \mathrm{KJ} / \mathrm{Kg}$ of work to be done on the process during start-ups. As the temperature increase, no work is further needed again as the value remain constant, indicates that once the process commenced, there is no immediate function of the $\mathrm{J}-\mathrm{T}$ valve required in the process as shown in Figure 4

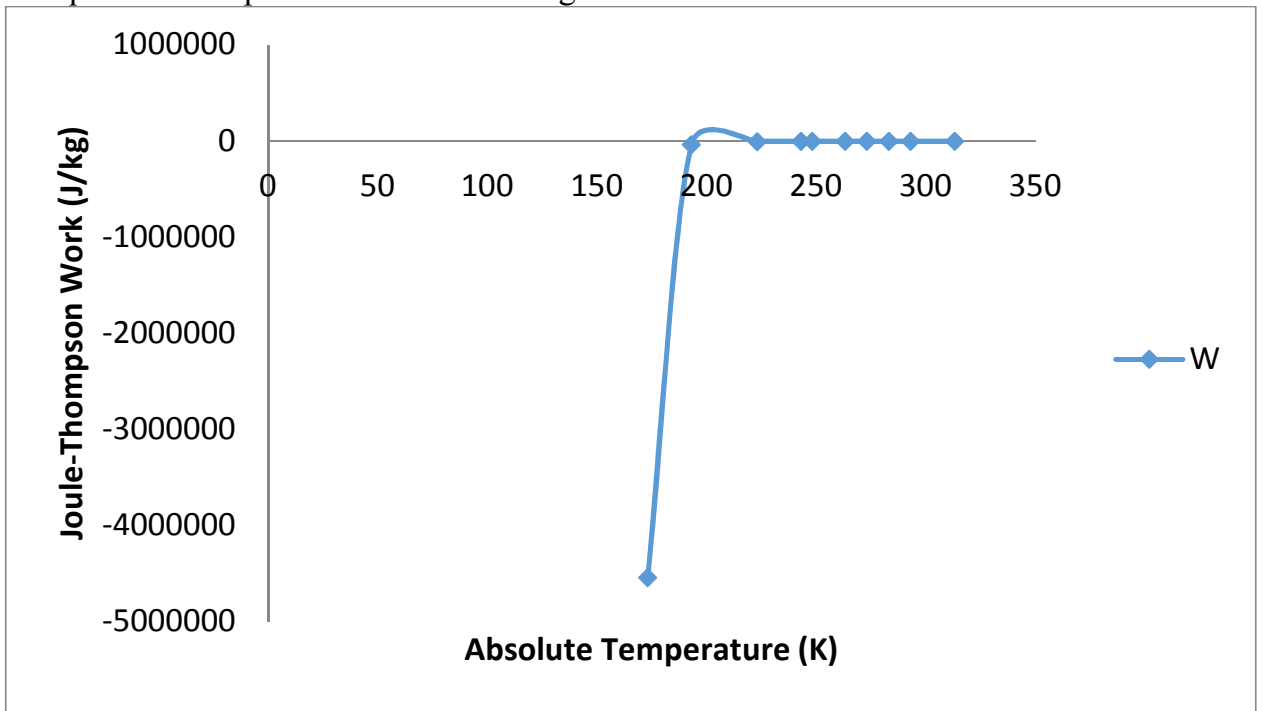

Figure 4: Variation of J-T Work versus Absolute Temperature

\subsection{Condenser and Reboiler}

Analysis of condenser and reboiler showed that the heat removed from the condenser is $3,180.5 \mathrm{~kW}$ and $1.65 \mathrm{~m}^{2}$ area was exchanged, while the heat for the reboiler is $474.5 \mathrm{~kW}$ at $47.25 \mathrm{~m}^{2}$ exchanged area.

\subsection{Demethanizer Column}

The product stream from the top of the column is the residue or sales gas, while the bottom product of the column is NGL. Thus, the temperature profile of the column is not uniform, because lower temperature is needed for the rectifying section (cryogenic absorption process), which when maintained at a range of $-90^{\circ} \mathrm{C}$ to $-95^{\circ} \mathrm{C}$ favours the production of sales gas as the top product stream, while a temperature range of $30^{\circ} \mathrm{C}$ to $36^{\circ} \mathrm{C}$ at the bottom favours the recovery of NGL product as the bottom stream. Thus, the design analysis of the demethanizer column yielded heights of distillation and absorption section as $28 \mathrm{~m}$ and $7.24 \mathrm{~m}$ while column diameter of $1.55 \mathrm{~m}$ and $3 \mathrm{~m}$ for distillation and absorption column respectively. 


\subsection{Costing of Equipment for NGL Recovery}

The equipments cost for this study was estimated and presented in Table 5

Table 5: Cost of Equipment

\begin{tabular}{|c|l|c|c|}
\hline \multirow{2}{*}{ S/N } & \multicolumn{1}{|c|}{ Parameter } & \multicolumn{2}{c|}{ Cost } \\
\cline { 3 - 4 } & & US(\$) & N470 per US(\$) \\
\hline 1 & Heat Exchangers & 89250 & 25882500 \\
\hline 2 & Separator & 5204.1 & 1509189 \\
\hline 3 & Condenser & 39000 & 11310000 \\
\hline 4 & Demethanizer-Distillation Column & 311800 & 90422000 \\
\hline 5 & Demethanizer-Absorber Column & 224750 & 65177500 \\
\hline 6 & Reboiler & 136500 & 39585000 \\
\hline
\end{tabular}

\section{Conclusion}

This study implemented internally generated heat energy from the NGL recovery process to meet heat energy requirements of the recovery process units with no external source of energy, thereby improving recovery process efficiency, effective process economics (minimization of operational cost) and a viable option for NGL recovery process and natural gas monetization in marginal field. The composition of study's product streams of sales gas and NGL showed high similarities in value with little or no deviation when compared with product streams of traditional process of external energy source. It is therefore recommended that the utilization of energy from produced sales gas should be used for utilities of the NGL recovery process, instead of energy produced from external source (steam generators). Also, organizations whose core business interest is NGL production should adopt this study in order to improve on the energy efficiencies and maximize profit, while detailed design, economics, and optimization of the recovery process by utilizing heat energy produced from sales gas should further be researched

\section{REFERENCES}

Ali, I. S., Mohammed, A. T., Ahamed, A. H. \& Ahmed, A. A. (2015). The Simulation of Natural Gas Liquids (NGL) Separation using Series of Distillation Columns. International Journal of Advanced Scientific and Technical Research, 5, 7, 154-161

Bhran, A. A., Hassanean, E.-K. \& Helal, M. H. (2016). Maximization of natural gas liquids production from an existing gas plant, Egyptian Journal of Petroleum, 25, 333-341

British Petroleum BP (2019). Statistical Review of World Energy: An Unstainable Path

Diaz, M. S., Serrani, A., Bandoni, J. A. \& Brignole, E. A. (1997). Automatic Design and Optimization of Natural Gas Plants, Industrial and Engineering Chemistry Research, 36, 2715-2724

Department of Petroleum Resources, DPR (2019). Nigeria's Gas Reserves Rise to 200.79 Trillion Cubic Feet. https://www.dpr.gov.ng/nigerias-gas-reserves-rise-to-200-79-trillion-cubic-feet-dpr/

Elliot, D., Qualls, W. R., Huang, S., Chen, J. J., Lee, R. J., Yao, J. \& Zhang, Y. (2005). Benefits of Integrating NGL Extraction and LNG Liquefaction Technology, Conference Proceedings of AIChE Spring Meeting, $1943-1958$

ENI Spa (2010). Natural Gas Monetization Option. ENI Spa Exploration and Production Division, Italy.

Ghorbani, B., Salehi, G. R. Ghaemmaleki, H. Amidpour, M. \& Hamedi; M. H. (2012). Simulation and Optimization of Refrigeration Cycle in NGL Recovery Plants with Exergy-Pinch Analysis, Journal of Natural Gas Science and Engineering, 7, 35-43

Halvorsen, I. J., Dejanovic, I., Olujic, Z. \& Skogestad, S. (2018). Dividing Wall Columns for Natural Gas Liquefaction Plants. Chemical Engineering Transactions, 69, 829-834

Jibril, K. L., Al-Humaizi, A. I., Idriss, A. A., \& Ibrahi, A. A. (2005). Simulation of Turbo-Expander Processes for Recovering of Natural Gas Liquids from Natural Gas. Saudi Aramco Journal of Technology, 2005, 9-14

Kidnay, A. J. \& Parrish, W. R. (2006). Fundamentals of Natural Gas Processing. Boca Raton: Taylor and Francis

Klemes, J., Friedler, F., Bulatov, I. \& Varbanov, P. (2010). Sustainability in the Process Industry: Integration and Optimization. New York: McGraw-Hill Publisher

Kofi, A.B. (2015). Maximization of National Gas Liquid Recovery of the Ghana National Gas Plant-ATUABO. Professional M.ENG with Management, Oil and Gas, Kwame Nkrumah University of Science and Technology, Kumasi: Ghana, 28-32

National Gas Policy (2017). Nigerian Government Policy and Action. http://www.petroleumindustrybill.com/wpcontent/uploads/2017/06/National-Gas-Policy-Approved-By-FEC-in-June-2017.pdf

Pinto, F. S., Zemp, R., Jobson, M. \& Smith, R. (2011). Thermodynamic Optimization of Distillation Columns, Chemical Engineering Science, 66, 2920-2934

Pitman, R. N., Hudson, H. M., Wilkinson, J. D. \& Cuella, K. T. (1998). Next Generation Processes for NGL/LPG Recovery. 77th Gas Processors Association (GPA) Annual Convention, Dallas: Texas, U.S.A. 
Rezakazemi, M., Heydari I. \& Zhang, Z. (2017). Hybrid Systems: Combining Membrane and Absorption Technologies leads to More Efficient Acid Gases $\left(\mathrm{CO}_{2}\right.$ and $\left.\mathrm{H}_{2} \mathrm{~S}\right)$ Removal from Natural Gas, Journal of CO Utilization, 18, 362-369

Sabbagh, O., Fanaei, M. A. \& Arjomand, A. (2020a). Optimal Design of a Novel NGL/LNG Integrated Scheme: Economic and Exergetic Condition. Journal of Thermal Analysis and Calorimetry, 145, 5

Sabbagh, O., Fanaei, M. A. \& Arjomand, A. (2020b). Techno-Economic Revolution of an Existing Operational NGL Plant with adding LNG Production Part. Oil \& Gas Science and Technology, 75, 27, 1-20

Saeid, M., William, P. \& Speight J. (2019). Handbook of Natural Gas Transmission and Processing. Canada: Gulf Professional Publishing

Tomlinson, T., Finn, A. \& Limb, D. (1990). Exergy Analysis in Process Development-introduction. The Chemical Engineer, 483, 25-30

Towler, G. \& Sinnott, R. (2013). Chemical Engineering Design Principles, Practice and Economics of Plant and Process Design. Oxford: Butterworth-Heinemann.

Triantafyllou, C. \& Smith, R. (1992). The Design and Optimisation of Fully Thermally Coupled Distillation Columns, Chemical Engineering Research and Design, 70, 118-132

U.S. Energy Information Administration (2018). Analysis based on Bloomberg data

US Department of Energy (2018). Natural Gas Liquids Primer: With a Focus on the Appalachian Region, ttps://www.energy.gov/sites/prod/files/2018/07/f54/NGL_Primer.pdf 